\title{
Extratos de plantas no controle de Rhipicephalus (Boophilus) microplus (Canestrini, 1887) (Acari: Ixodidae) em laboratório
}

\author{
Plant extracts in control of Rhipicephalus (Boophilus) microplus (Canestrini, 1887) \\ (Acari: Ixodidae) in laboratory \\ Sônia Maria Forti Broglio-Micheletti ${ }^{1 *}$; Ellen Carine Neves Valente²; \\ Leilianne Alves de Souza ${ }^{2}$; Nivia da Silva Dias ${ }^{3}$; Alice Maria Nascimento de Araújo ${ }^{4}$
}

${ }^{1}$ Centro de Ciências Agrárias - CECA, Universidade Federal de Alagoas - UFAL

${ }^{2}$ Curso de Agronomia, Centro de Ciências Agrárias - CECA, Universidade Federal de Alagoas - UFAL

${ }^{3}$ Laboratório de Entomologia, Unidade Acadêmica de Ciências Agrárias, Universidade Federal de Alagoas - UFAL

${ }^{4}$ Mestrado em Produção Vegetal, Centro de Ciências Agrárias - CECA, Universidade Federal de Alagoas - UFAL

Recebido em 14 de Abril de 2009

Aceito em 1 de Junho de 2009

\section{Resumo}

Extratos vegetais foram estudados com o objetivo de avaliar suas eficiências no controle de Rhipicephalus (Boophilus) microplus (Canestrini, 1887) em laboratório. Fêmeas ingurgitadas de carrapato foram coletadas de bovinos e mantidas em placas de Petri. Foram utilizados extratos orgânicos alcoólicos 2\% (peso/volume) de sementes de Annona muricata L. (Annonaceae) (graviola); flores de Syzygium malaccensis (L.) (Myrtaceae) (jambo); folhas de Cymbopogon citratus (DC.) Stapf (Poaceae) (capim-santo); folhas de Azadirachta indica A. Juss (Meliaceae) (nim); e extrato hexânico na mesma concentração de $A$. indica (sementes). Os grupos-controle foram compostos por fêmeas sem tratamento e fêmeas tratadas com água destilada e esterilizada e dimetilsulfóxido (DMSO) a uma concentração de $1 \%$. O extrato de A. muricata apresentou o maior poder acaricida, com eficácia de $100 \%$, seguido dos extratos de S. malaccensis (75 e $59,24 \%$ ) e $A$. indica (65 e 38,49\%). Houve $100 \%$ de reduçáo na eclosão das larvas quando se utilizou o extrato de sementes de $A$. muricata.

Palavras-chave: Carrapato, Annona muricata, Syzygium malaccensis, Azadirachta indica, Cymbopogon citratus.

\begin{abstract}
Plant extracts were studied to evaluate its efficiency in the control of Rhipicephalus (Boophilus) microplus (Canestrini, 1887) in laboratory. Engorged female ticks were collected from the cattle, kept in Petri dishes. Organic alcoholic extracts 2\% (weight/volume) were used: seeds of Annona muricata L. (Annonaceae) (soursop); flowers of Syzygium malaccensis (L.) (Myrtaceae) (iamb), leaves of Cymbopogon citratus (DC.) Stapf (Poaceae) (holy grass), leaves of Azadirachta indica A. Juss (Meliaceae) (neem) and hexane extract 2\% (weight/volume) of $A$. indica (seeds). The control groups consisted of untreated females and females treated with distilled water and sterile and dimethylsulfoxide (DMSO) a concentration of $1 \%$. The extract of $A$. muricata (seed) had the highest mortality with acaricide activity and $100 \%$ efficacy followed by extracts of S. malaccensis (75 and 59.24\%) and $A$. indica (65 and 38.49\%). The seed extract of A. muricata reduced $100 \%$ larvae hatch.
\end{abstract}

Keywords: Tick, Annona muricata, Syzygium malaccensis, Azadirachta indica, Cymbopogon citratus.

\section{Introdução}

Os carrapatos estão incluídos entre os agentes etiológicos responsáveis por problemas sanitários na bovinocultura. Em geral, de difícil controle, trazem prejuízos econômicos à exploração leiteira,

\footnotetext{
*Autor para correspondência: Sônia Maria Forti Broglio-Micheletti Centro de Ciências Agrárias - CECA,

Universidade Federal de Alagoas - UFAL, Campus Delza Gitaí, Rod. BR 104,

Km 85, sem número, CEP 57.100-000, Rio Largo - AL, Brasil;

e-mail: soniamfbroglio@gmail.com
}

redução de produção de leite, baixa conversão alimentar e ganho de peso, por causa da mortalidade e consequente perda de material genético, além de custos diretos e indiretos com o tratamento e profilaxia de doenças infecto-parasitárias (VIDOTTO, 2002).

O controle do carrapato bovino é geralmente efetuado por meio de produtos químicos convencionais, os quais acarretam em dois grandes problemas: o desenvolvimento acelerado da resistência ao princípio ativo e os resíduos nos produtos de origem animal, 
que têm provocado grande preocupação na sociedade e órgãos governamentais (LEAL et al., 2003). O uso incorreto do carrapaticida (subdose, preparo inadequado, aplicação mal feita) faz com que os carrapatos náo morram após contato com o produto. Cada vez que os carrapatos sobrevivem a uma aplicação de carrapaticida, eles transmitem às geraçôes posteriores informaçóes genéticas de como sobreviver àquele produto (FURLONG; PRATA, 2006).

As plantas têm sido uma importante fonte de substâncias com diferentes estruturas químicas e com diversas atividades contra artrópodes (VIVAN, 2005). Dessa forma, acredita-se que o uso de extratos vegetais de uma forma isolada ou associada pode causar um desenvolvimento bem mais lento da resistência. Outro fator importante é a redução do problema de resíduos bem como sua característica biodegradável.

A utilização de extratos vegetais no controle do carrapato também tem sido foco de pesquisas em vários países (CHUNGSAMARNYART et al., 1991; WILLIAMS, 1993; VATSYA et al., 2006; ÁLVAREZ et al., 2008). No Brasil, trabalhos que utilizam óleos emulsionáveis de eucalipto (Eucalyptus spp.) (Myrtaceae), rotenoides extraídos do timbó (Derris urucu) (Fabaceae) (VERÍSSIMO, 2004) e azadiractina, presente em plantas da família Meliaceae (Melia azedarach) (BORGES et al., 2003), mostraramse promissores no controle desse parasito.

As plantas da família Meliaceae são as mais exploradas por possuírem compostos secundários, que são encontrados nas várias partes da planta, principalmente folhas, frutos e sementes. $\mathrm{O}$ nim, Azadirachta indica A. Juss, é a espécie botânica atualmente mais estudada e classificada como um pesticida de alta eficiência e baixo efeito residual (AGUIAR-MENEZES, 2005). Extratos desta planta podem ser utilizados para o controle de determinadas espécies de carrapatos como Hyalomma anatolicum excavatum Koch (Acarina: Ixodidae), Amblyomma americanum L. (Acarina: Ixodidae) e Dermacentor variabilis Say (Acarina: Ixodidae) (SANTOS et al., 2006).

Em Cymbopogon citratus (DC.) Stapf (Poaceae) (capim-santo), dentre outras substâncias, são encontrados flavonoides, alcaloides e triterpenos, o que lhe confere várias atividades como antibacteriano, antifúngico, inseticida, diurético, anti-carcinogênico, hipotensivo e anti-inflamatório (SILVA et al., 2005).

As anonáceas têm sido muito pesquisadas devido ao isolamento e caracterização de diversas classes de substâncias com atividades químicas e farmacológicas, principalmente no que diz respeito às acetogeninas (LEBOEUF et al., 1982). Porém não há relatos sobre o uso no controle do carrapato bovino, o mesmo ocorrendo com Syzygium malaccensis (L.) (Myrtaceae) (jambo). Estudos químicos efetuados com as folhas de $S$. malaccensis levaram ao isolamento de quatro flavonoides: catequina, mearnsitrina, miricitrina e quercitrina. Dos frutos foram obtidos compostos voláteis. A partir das flores, foi isolada a antocianina, 3,5-diglicosílmalvidina, enquanto do caule foram isolados os ácidos elágico, 3-Ometilelágico (OLIVEIRA et al., 2006).

O presente trabalho foi realizado com os objetivos de estudar, em laboratório, a mortalidade (\%) e o tempo letal (dias) de fêmeas ingurgitadas de $R$. (B.) microplus submetidas a diferentes extratos vegetais em testes de imersão, bem como o número de posturas oriundas dessas fêmeas, peso dos ovos $(\mathrm{mg})$ ), eclosão (eclodibilidade larval) (\%) e eficiência do controle (\%).

\section{Material e Métodos}

Os bioensaios foram conduzidos no Laboratório de Entomologia do Centro de Ciências Agrárias da Universidade Federal de Alagoas (CECA, UFAL), localizado no município de Rio Largo, AL $\left(9^{\circ} 27^{\prime} \mathrm{S}\right.$ e $35^{\circ} 27^{\prime} \mathrm{O}$, altitude $\left.127 \mathrm{~m}\right)$, à temperatura média de $27,6 \pm 1{ }^{\circ} \mathrm{C}$ e uma umidade relativa média de $77,4 \%$, no período de março a abril de 2008.

As plantas utilizadas foram: folhas de $A$. indica (nim) e C. citratus (capim-santo), sementes de $A$. muricata (graviola) e flores de S. malaccensis (jambo). Após as confirmaçôes taxonômicas das referidas plantas, uma exsicata de cada uma delas foi depositada no herbário do IMA, Maceió.

Todos os extratos foram preparados no Laboratório de Produtos Naturais, do Instituto de Química e Biotecnologia da UFAL. Os extratos etanólicos das flores do jambo e extrato hexânico de semente de nim foram previamente preparados, no ano de 2007, e conservados em geladeira. Após a coleta das partes vegetais, foi realizada a secagem em estufa com circulação e renovação de ar a 40-45 ${ }^{\circ} \mathrm{C}$, durante 48 horas e, em seguida, fez-se a trituração em moinho de facas para obtenção de pó fino, o qual foi imerso em álcool etílico hidratado (92,80 INPM), na proporção de 1 parte de pó para 3 partes do solvente, durante 48 horas. Após esse período, a suspensão e a evaporação do solvente foram realizadas em evaporador rotativo a vácuo. Esse procedimento foi realizado duas vezes para maior extração dos princípios ativos. Após a evaporação de todo o solvente, os respectivos extratos foram acondicionados em geladeira $\left( \pm 5^{\circ} \mathrm{C}\right)$ para evitar proliferação de microrganismos.

As fêmeas ingurgitadas de $R$. (B.) microplus foram coletadas em animais isentos de carrapaticida químico de contato por pelo menos 30 dias, tendo-se o cuidado de separar as fêmeas (maiores que $5 \mathrm{~mm}$ em comprimento). As teleóginas coletadas foram acondicionadas em placas de Petri e transportadas em caixa térmica contendo gelo, para evitar uma prematura oviposiçáo e reduzir a mobilidade do parasito dentro das placas. A classificação taxonômica dos carrapatos foi baseada em Cordovés (1997), separando-se os exemplares pelo gnatossoma (capítulo), para que o trabalho fosse realizado somente com $R$. (B.) microplus.

O delineamento experimental foi inteiramente casualizado com sete tratamentos e quatro repetiçóes, considerando-se cinco fêmeas ingurgitadas como repetição. $\mathrm{O}$ primeiro grupo controle foi representado por teleóginas isentas de quaisquer tratamentos e, o segundo, por fêmeas tratadas com água destilada e esterilizada em que se adicionou o solubilizador DMSO em concentração de $1 \%$. Os demais tratamentos foram compostos por extratos orgânicos alcoólicos 2\% (peso/volume) de sementes de graviola; flores de jambo; folhas de capim-santo; folhas de nim; e extrato hexânico na mesma concentração de nim (sementes), os quais foram, no momento da montagem do bioensaio, solubilizados em 1\% de DMSO e diluídos em água destilada e esterilizada, formando assim uma solução de $100 \mathrm{~mL}$, na qual 20 fêmeas foram imersas durante 5 minutos. Após a secagem, foram transferidas para placas de Petri, em grupos de cinco fêmeas ingurgitadas por placa e mantidas em condiçóes ambientais.

As coletas de dados foram feitas a partir do terceiro dia da montagem do bioensaio, quando as fêmeas iniciaram a oviposição. 
Foram registradas, a cada três ou quatro dias até as primeiras eclosões larvais, a mortalidade das fêmeas (observada pela reação ao toque com uma pinça), o tempo letal (período decorrido entre a imersão e a morte), o número de oviposiçôes, o peso dos ovos e o percentual de eclodibilidade (14 dias após a última pesagem da massa de ovos) por intermédio de uma escala de notas que variou de 0 (ausência de eclodibilidade) a 4 (100\% de eclodibilidade) e eficiência do produto. Os cálculos para eficácia do produto (EP) foram avaliados segundo as equaçóes prescritas por Drummond et al. (1973).

\section{Resultados e Discussáo}

A mortalidade variou de 5 a $100 \%$, alcançando valores estatisticamente iguais para flor do jambo (75\%) e semente de graviola $(100 \%)$, que foram os tratamentos mais promissores (Tabela 1). Em relaçáo ao tempo letal, o jambo (flor) e a graviola (semente) mataram 30 e $60 \%$, respectivamente, das fêmeas aos 3 dias após a imersão, diferindo dos demais tratamentos, e aos 6 dias, o extrato de semente da graviola matou mais 25\% das fêmeas, diferindo dos demais tratamentos (Tabela 2). Aos 10, 13, 17 dias não houve diferença entre os tratamentos. Porém, aos 21 dias, a fraçáo hexânica do nim matou $50 \%$ das fêmeas, perfazendo um total de 65\% de fêmeas mortas (10-21 dias). Nos grupos-controle, as primeiras mortes foram observadas a partir do $13^{\circ} \mathrm{dia}$. O extrato etanólico das folhas de capim-santo foi menos eficiente na concentração utilizada (2\%), apresentando mortalidade de 45\% das teleóginas; porém, Heimerdinger (2005), analisando a eficácia de extratos alcoólicos obtidos a partir da maceração de raízes, rizomas, colmos e folhas da mesma planta no controle da infestação natural de bovinos por $R$. (B.) microplus, concluiu que a solução contendo $2,72 \%$ de capim-santo reduziu a infestação em 40,33; 46,56; 41,46\% nos dias 3, 7 e 14 pós-tratamento, respectivamente.

Em relação à oviposição com o extrato de semente de graviola, verificou-se grande potencial na reduçáo do número total de posturas $(2,00)$, diferindo dos demais tratamentos, enquanto as testemunhas tiveram 26,00 e 28,00 (sem tratamento e água + DMSO, respectivamente). Quanto ao peso médio dos ovos, também $A$. muricata teve o menor valor com $0,03 \mathrm{~g}$, diferindo dos demais tratamentos, enquanto as testemunhas tiveram 0,53 e $0,55 \mathrm{~g}$, respectivamente (Tabela 1). Borges et al. (2003), trabalhando com extrato de Melia azedarach (Meliaceae) (cinamomo) a $0,25 \%$, observaram, in vitro, inibição total da oviposiçẫo em fêmeas ingurgitadas imersas no extrato bruto de frutos maduros extraídos com diferentes solventes e verificaram elevada taxa de mortalidade de larvas e alta eficácia sobre fêmeas ingurgitadas, sendo que o extrato não matou as fêmeas adultas, mas inibiu total ou parcialmente a produção de ovos e a embriogênese.

O extrato da semente da graviola foi o único que diferiu estatisticamente dos demais tratamentos em relação à eclosão larval, pois não se constatou eclosão nesse grupo (Tabela 1). Contudo, apesar do bom desempenho do extrato de $A$. muricata, não há

Tabela 1. Médias ${ }^{1} \pm$ (erro-padrão) da mortalidade das teleóginas, número total de oviposiçóes, peso dos ovos, porcentagem de eclodibilidade e eficiência do produto em fêmeas ingurgitadas de Rhipicephalus (Boophilus) microplus após a imersão em extratos vegetais.

\begin{tabular}{|c|c|c|c|c|c|}
\hline Tratamentos & $\begin{array}{c}\text { Mortalidade } \\
(\%)\end{array}$ & $\begin{array}{l}\text { No total de } \\
\text { oviposiçóes }\end{array}$ & $\begin{array}{c}\text { Peso dos ovos } \\
(\mathrm{g})\end{array}$ & $\begin{array}{c}\text { Eclosáo } \\
(\%)\end{array}$ & $\begin{array}{c}\text { Eficácia do } \\
\text { produto }(\%)\end{array}$ \\
\hline Testemunha sem tratamento & $25,00 \pm 10,20^{\mathrm{ab}}$ & $26,00 \pm 0,25^{\mathrm{cd}}$ & $0,53 \pm 0,03^{d}$ & $76,00 \pm 4,22^{b c}$ & - \\
\hline Testemunha + água + DMSO & $5,00 \pm 5,00^{a}$ & $28,00 \pm 0,29^{d}$ & $0,55 \pm 0,02^{\mathrm{d}}$ & $69,55 \pm 4,24^{\mathrm{bc}}$ & $10,00 \pm 4,83^{\mathrm{ab}}$ \\
\hline Capim-santo (folha) $2 \%^{2}$ & $45,00 \pm 4,00^{\mathrm{bc}}$ & $23,00 \pm 0,87^{\mathrm{cd}}$ & $0,44 \pm 0,02^{\text {cd }}$ & $74,50 \pm 3,33^{\mathrm{bc}}$ & $18,35 \pm 3,95^{\mathrm{abc}}$ \\
\hline Jambo (flor) $2 \%^{2}$ & $75,00 \pm 5,50^{c}$ & $12,00 \pm 1,35^{b}$ & $0,24 \pm 0,03^{\mathrm{b}}$ & $52,55 \pm 90,22^{b}$ & $59,24 \pm 13,02^{\text {cd }}$ \\
\hline Nim (semente) $2 \%^{3}$ & $65,00 \pm 5,55^{b c}$ & $19,00 \pm 1,50^{c}$ & $0,34 \pm 0,02^{\mathrm{bc}}$ & $64,50 \pm 6,51^{b}$ & $38,49 \pm 5,30^{\mathrm{bcd}}$ \\
\hline Graviola (semente) $2 \%^{2}$ & $100,00 \pm 0,00^{c}$ & $2,00 \pm 1,03^{\mathrm{a}}$ & $0,03 \pm 0,01^{\mathrm{a}}$ & $0,00 \pm 0,00^{a}$ & $100,00 \pm 0,00^{\mathrm{d}}$ \\
\hline Nim (folha) $2 \%^{2}$ & $65,00 \pm 17,00^{\mathrm{bc}}$ & $21,00 \pm 1,11^{\mathrm{cd}}$ & $0,45 \pm 0,03^{\mathrm{d}}$ & $76,55 \pm 5,18^{b c}$ & $2,38 \pm 0,54^{\mathrm{ab}}$ \\
\hline CV(\%) 15,28 & & 7,80 & 18,62 & 11,07 & 25,24 \\
\hline
\end{tabular}

${ }^{1}$ Médias seguidas pela mesma letra nas colunas nẫo diferem estatisticamente entre si pelo teste de Tukey a 5\% de probabilidade (P $\left.\leq 0,05\right)$; - Não se aplica; ${ }^{2}$ Fração etanólica; ${ }^{3}$ Fração hexânica; CV - Coeficiente de Variação.

Tabela 2. Médias ${ }^{1}$ da mortalidade $(\%) \pm$ (erro-padrão) no período de 3 a 21 dias após a imersão nos extratos vegetais de fêmeas ingurgitadas de Rhipicephalus (Boophilus) microplus.

\begin{tabular}{|c|c|c|c|c|c|c|c|}
\hline \multirow{2}{*}{ Tratamentos } & \multicolumn{7}{|c|}{ Dias após imersáo } \\
\hline & 3 & 6 & 10 & 13 & 17 & 21 & CV $(\%)$ \\
\hline Testemunha sem tratamento & $0,0 \pm 0,0^{\mathrm{a}}$ & $0,0 \pm 0,0^{\mathrm{a}}$ & $0,0 \pm 0,0^{\mathrm{a}}$ & $5,0 \pm 5,0^{a}$ & $5,0 \pm 5,0^{\mathrm{a}}$ & $15,0 \pm 9,6^{\mathrm{ab}}$ & 17,25 \\
\hline Testemunha + água + DMSO & $0,0 \pm 0,0^{\mathrm{a}}$ & $0,0 \pm 0,0^{\mathrm{a}}$ & $0,0 \pm 0,0^{\mathrm{a}}$ & $5,0 \pm 0,0^{a}$ & $0,0 \pm 0,0^{\mathrm{a}}$ & $5,0 \pm 5,0^{\mathrm{a}}$ & 11,94 \\
\hline Capim-santo (folha) $2 \%^{2}$ & $0,0 \pm 0,0^{\mathrm{a}}$ & $0,0 \pm 0,0^{\mathrm{a}}$ & $5,0 \pm 5,0^{a}$ & $0,0 \pm 0,0^{a}$ & $0,0 \pm 0,0^{\mathrm{a}}$ & $40,0 \pm 0,0^{\mathrm{ab}}$ & 7,42 \\
\hline Jambo (flor) $2 \%^{2}$ & $30,0 \pm 10,0^{\mathrm{b}}$ & $0,0 \pm 0,0^{\mathrm{a}}$ & $0,0 \pm 0,0^{\mathrm{a}}$ & $5,0 \pm 5,0^{a}$ & $15,0 \pm 9,6^{a}$ & $25,0 \pm 5,0^{\mathrm{ab}}$ & 20,02 \\
\hline Nim (semente) $2 \%^{3}$ & $0,0 \pm 0,0^{\mathrm{a}}$ & $0,0 \pm 0,0^{\mathrm{a}}$ & $5,0 \pm 5,0^{a}$ & $5,0 \pm 5,0^{a}$ & $5,0 \pm 5,0^{\mathrm{a}}$ & $50,0 \pm 5,8^{b}$ & 13,41 \\
\hline Graviola (semente) $2 \%^{2}$ & $60,0 \pm 0,0^{c}$ & $25,0 \pm 5,0^{\mathrm{b}}$ & $5,0 \pm 5,0^{a}$ & $0,0 \pm 0,0^{\mathrm{a}}$ & $5,0 \pm 5,0^{a}$ & $5,0 \pm 5,0^{\mathrm{a}}$ & 13,47 \\
\hline Nim (folha) $2 \%^{2}$ & $0,0 \pm 0,0^{\mathrm{a}}$ & $0,0 \pm 0,0^{a}$ & $5,0 \pm 5,0^{\mathrm{a}}$ & $0,0 \pm 0,0^{\mathrm{a}}$ & $25,0 \pm 9,6^{a}$ & $35,0 \pm 17,0^{\mathrm{ab}}$ & 23,26 \\
\hline
\end{tabular}

${ }^{1}$ Médias seguidas pela mesma letra nas colunas não diferem estatisticamente entre si pelo teste de Tukey a $5 \%$ de probabilidade $(\mathrm{P} \leq 0,05) ;{ }^{2}$ Fração etanólica, ${ }^{3}$ Fração hexânica; CV - Coeficiente de Variação. 
relatos da influência das acetogeninas de anonáceas sob a eclosão das larvas de $R$. (B.) microplus.

Analisando-se a eficácia dos extratos botânicos, observou-se que o extrato da folha do nim foi o menos promissor $(2,38 \%)$, contrapondo-se ao extrato da semente da graviola que apresentou $100 \%$ de eficiência. Segundo Aguiar-Menezes (2005), em insetos, a azadirachtina inibe a biossíntese do hormônio protoracicotrópico (PTTH) e, como consequência, não ocorre a biossíntese de outros hormônios, o que impossibilita os passos normais da troca de tegumento (ecdise) e também inibe a maturação dos ovos. Os extratos da flor do jambo $(59,24 \%)$, bem como do nim fraçáo hexânica $(38,49 \%)$, obtiveram resultados intermediários. Os extratos da flor do jambo, nim (fração hexânica) e graviola não diferiram entre si (Tabela 1). Martins e González (2007), trabalhando com óleo essencial de Cymbopogon winterianus Jowitt (Panicoidideae) (citronela de Java) in vivo, aplicado puro na linha dorsal do animal e por via de aspersão do óleo diluído em álcool na proporçáo de 1:10 observaram que ambos os tratamentos foram eficientes no controle do carrapato bovino, não sendo tóxicos para os animais, diferentemente do que foi observado nesse bioensaio em laboratório, pois o $C$. citratus, planta do mesmo gênero botânico, apresentou apenas 18,35\% de eficácia. Valente et al. (2007) compararam in vivo a eficácia do extrato aquoso de folhas frescas de nim (1 kg de folhas frescas: $5 \mathrm{~L}$ de água), aplicado em banhos semanais (2L/animal) durante um mês, com a da abamectina em aplicação uma vez no dorso, para controle de $R$. $(B)$. microplus. Constataram que não houve diferença na infestação entre os grupos, podendo o extrato vegetal substituir a abamectina dentro de um programa zootécnico de controle dos carrapatos no semiárido.

Sousa et al. (2008), trabalhando com extratos oleosos hexânicos de frutos verdes e maduros de cinamomo em triplicata, em diluições de 0,25 a 0,0156\%, sobre fêmeas ingurgitadas e larvas do carrapato bovino, observaram que o extrato de frutos verdes apresentou uma eficácia que variou de 3,6 a 100\% para as fêmeas, e o de frutos maduros variou de 5,2 a 99,7\%. Ambos os extratos (frutos verdes e maduros) causaram mortalidade de 100\% das larvas nas maiores concentraçóes, demonstrando superioridade em relação ao extrato de frutos maduros. Os resultados obtidos demonstram uma superioridade do extrato de frutos verdes, com uma menor DL50 e potência 1,497 vezes superior ao extrato de frutos maduros.

Com base nos resultados deste trabalho, pode-se indicar que os extratos das sementes da graviola e da flor do jambo, em concentração de $2 \%$, possuem significativo potencial de controle do carrapato bovino, pois, além de causar a mortalidade das teleóginas nos primeiros dias após o tratamento, interferem na sua reproduçáo, podendo ser uma alternativa aos carrapaticidas químicos normalmente utilizados. Uma forma de reduzir a quantidade de matéria prima a ser utilizada quando in vivo, é aplicar os fundamentos do manejo integrado de pragas, em que o potencial de determinado método de controle pode ser incrementado com a associação de outros métodos.

$\mathrm{O}$ extrato da semente de graviola apresentou melhor desempenho in vitro para o controle de $R$. (B.) microplus, pois, além do alto índice de mortalidade e rápido efeito sobre as fêmeas ingurgitadas, apresentou maior eficiência do produto, além de reduzir acentuadamente a oviposição das teleóginas, bem como a eclodibilidade larval. Contudo, para que o extrato de semente de graviola $2 \%$ seja recomendado para o controle de $R$. (B.) microplus, são necessários novos estudos com seu uso in vivo.

\section{Agradecimentos}

À Pesquisadora do Instituto do Meio Ambiente Maria Noêmia Rodrigues, pelas confirmaçóes taxonômicas das plantas e à Professora Dra. Maria Aparecida da Glória Faustino da Universidade Federal Rural de Pernambuco, pela confirmação específica dos carrapatos.

\section{Referências}

AGUIAR-MENEZES, E. L. Inseticidas Botânicos: seus princípios ativos, modo de ação e uso agrícola. Seropédica: Embrapa Agrobiologia, 2005. 58 p. (Documentos, 205).

ÁLVAREZ, V. et al. Control in vitro de garrapatas (Boophilus microplus; Acari: Ixodidae) mediante extractos vegetales. Revista de Biologia Tropical, v. 56, n. 1, p. 291-302, 2008.

BORGES, L. M. F. et al. In vitro efficacy of extracts of Melia azedarach against the tick Boophilus microplus. Medical and Veterinary Entomology, v. 17, n. 2, p. 228-231, 2003.

CHUNGSAMARNYART, N.; JIWAJINDA, S.; JANSAWAN, W. Acaricidal effect of plant crude-extracts on tropical cattle tick (Boophilus microplus). Kasetsart Journal, (Natural Sciences Supplement), v. 25, p. 90-100, 1991.

CORDOVÉS, C. O. Carrapato: controle ou erradicação. 2 ed. Guaíba: Agropecuária, 1997. $176 \mathrm{p}$.

DRUMMOND, R. O. et al. Boophilus annulatus and B. microplus laboratory tests of insecticides. Journal of Economic Entomology, v. 66, n. 1, p. 130-133, 1973.

FURLONG, J.; PRATA, M. Controle estratégico do carrapato dos bovinos de leite. Juiz de Fora: EMBRAPA-CNPGL, 2006. 2 p. (Circular Técnica, 38).

HEIMERDINGER, A. Extrato alcoólico de capim-cidreira (Cymbopogon citratus) no controle do carrapato (Boophilus microplus) de bovinos leiteiros. Santa Maria, 2005. 78 p. Dissertação (Mestrado em Zootecnia) - Universidade Federal de Santa Maria, Rio Grande do Sul.

LEAL, A. T.; FREITAS, D. R. J. de; VAZ JÚNIOR, I. da S. Perspectivas para o controle do carrapato bovino. Acta Scientiae Veterinariae, v. 31, n. 1, p. 1-11, 2003.

LEBOEUF, M. et al. The phytochemistry of the annonaceae. Phytochemistry, v. 21, n. 12, p. 2783-2813, 1982.

MARTINS, R. M.; GONZÁLEZ, F. H. D. Uso del aceite de citronela de Java (Cymbopogon winterianus Jowitt (Panicoidideae) como acaricida frente a la garrapata Boophilus microplus Canestrini (Acari: Ixodidae). Revista Brasileira de Plantas Medicinais, v. 9, n. 4, p. 1-8, 2007.

OLIVEIRA, A. M. et al. Estudo fitoquímico e avaliaçáo das atividades moluscicida e larvicida dos extratos da casca do caule e folha de Eugenia malaccensis L. (Myrtaceae). Revista Brasileira de Farmacognosia, v. 16, suplemento, p. 618-624, 2006. 
SANTOS, A. C. G. et al. Uso de Extrato de Nim no Controle de Acaríase por Myobia musculi Schranck (Acari: Miobidae) e Myocoptes musculinus Koch (Acari: Listrophoridae) em Camundongos (Mus musculus var. albina L.). Neotropical Entomology, v. 35, n. 2, p. 269-272, 2006.

SILVA, W. W. et al. Ação do extrato alcoólico do capim santo (Cymbopogon citratus (DC) Stapf) sobre nematóides gastrintestinais de ovinos. Agropecuária Científica no Semi-Árido, v. 1, p. 46-49, 2005.

SOUSA, L. A. D. et al. Avaliação da eficácia de extratos oleosos de frutos verdes e maduros de cinamomo (Melia azedarach) sobre Rhipicephalus (Boophilus) microplus (Acari: Ixodidae). Revista Brasileira de Parasitologia Veterinária, v. 17, n. 1, p. 36-40, 2008.

VALENTE, M.; BARRANCO, A.; SELLAIVE-VILLAROEL, A. B. Eficácia do extrato aquoso de Azadiracta indica no controle de Boophilus microplus em bovino. Arquivo Brasileiro de Medicina Veterinária e Zootecnia, v. 59, n. 5, p. 1341-1343, 2007.
VATSYA, S. et al. In vitro acaricidal effect of some medicinal plantas against Boophilus microplus. Journal of Veterinary Parasitology, v. 20, n. 2, p. 141-143, 2006.

VERÍSSIMO, C. J. Controle biológico e alternativo do carrapato do boi. São Paulo: APTA/SAA-SP, 2004. 3 p.

VIDOTTO, O. Complexo Carrapato - Tristeza Parasitária e outras parasitoses de bovinos, 2002. Disponível em: http://www.nupel.uem. br/pos-ppz/complexo-08-03.pdf. Acesso em: 23 Julho 2008.

VIVAN, M. P. Uso do cinamomo (Melia azedarach) como alternativo aos agroquímicos no controle do carrapato bovino (Boophilus microplus). Florianópolis, 2005. 72 p. Dissertação (Mestrado) - Universidade Federal de Santa Catarina.

WILLIAMS, L. A. D. Adverse effects of extracts of Artocarpus altilis Park. and Azadirachta indica A. Juss. on the reproductive physiology of the adult female tick, Boophilus microplus (Canest.). Invertebrate Reproduction and Development, v. 23, n. 2-3, p. 159-164, 1993. 